\title{
Selective Limbic Blood-Brain Barrier Breakdown in a Feline Model of Limbic Encephalitis with LGI1 Antibodies
}

\author{
Anna R. Tröscher ${ }^{1}$, Andrea Klang ${ }^{2}$, Maria French ${ }^{1}$, Lucía Quemada-Garrido', \\ Sibylle Maria Kneiss/ ${ }^{3}$, Christian G. Bien ${ }^{4}$, Ákos Pákozdy ${ }^{5 \dagger}$ and Jan Bauer ${ }^{1 *}$
}

\begin{abstract}
'Department of Neuroimmunology, Center for Brain Research, Medical University of Vienna, Vienna, Austria, ${ }^{2}$ Department for Pathobiology, Institute of Pathology and Forensic Veterinary Medicine, University of Veterinary Medicine, Vienna, Austria, ${ }^{3}$ Diagnostic Imaging, Department for Companion Animals and Horses, University of Veterinary Medicine, Vienna, Austria, ${ }^{4}$ Epilepsy Center Bethel, Krankenhaus Mara, Bielefeld, Germany, ${ }^{5}$ Clinical Unit of Internal Medicine Small Animals, University of Veterinary Medicine, Vienna, Austria
\end{abstract}

Human leucine-rich glioma-inactivated protein 1 encephalitis (LGl1) is an autoimmune limbic encephalitis in which serum and cerebrospinal fluid contain antibodies targeting LGI1, a protein of the voltage gated potassium channel (VGKC) complex. Recently, we showed that a feline model of limbic encephalitis with LGI1 antibodies, called feline complex partial seizures with orofacial involvement (FEPSO), is highly comparable to human LGl1 encephalitis. In human LGl1 encephalitis, neuropathological investigations are difficult because very little material is available. Taking advantage of this natural animal model to study pathological mechanisms will, therefore, contribute to a better understanding of its human counterpart. Here, we present a brain-wide histopathological analysis of FEPSO. We discovered that blood-brain barrier (BBB) leakage was present not only in all regions of the hippocampus but also in other limbic structures such as the subiculum, amygdale, and piriform lobe. However, in other regions, such as the cerebellum, no leakage was observed. In addition, this brain-region-specific immunoglobulin leakage was associated with the breakdown of endothelial tight junctions. Brain areas affected by BBB dysfunction also revealed immunoglobulin and complement deposition as well as neuronal cell death. These neuropathological findings were supported by magnetic resonance imaging showing signal and volume increase in the amygdala and the piriform lobe. Importantly, we could show that BBB disturbance in LGl1 encephalitis does not depend on T cell infiltrates, which were present brain-wide. This finding points toward another, so far unknown, mechanism of opening the BBB. The limbic predilection sites of immunoglobulin antibody leakage into the brain may explain why most patients with LGl1 antibodies have a limbic phenotype even though LGl1, the target protein, is ubiquitously distributed across the central nervous system.

Keywords: hippocampus, amygdala, tight junctions, limbic encephalitis, neuroinflammation

Abbreviations: AMPAR, $\alpha$-amino-3-hydroxy-5-methyl-4-isoxazolepoionic acid receptor; BBB, blood-brain barrier; FEPSO, feline complex partial seizures with orofacial involvement; FLAIR, Fluid attenuation inversion recovery; vWF, von Willebrand factor; $\mathrm{GABA}_{\mathrm{B}} \mathrm{R}$, gamma aminobutyric acid $\mathrm{B}$ receptor; HN, hippocampal necrosis; HS, hippocampal sclerosis; LGI1, leucine-rich glioma-inactivated protein 1; MAP-2, myelin-associated protein 2; NeuN, neuronal nuclei; NMDAR, $N$-methylD-aspartate receptor; TG2, transglutaminase 2; TUNEL, terminal deoxynucleotidyl transferase dUTP nick end labeling; VGKC, voltage-gated potassium channel complex; ZO-1, zona occludens 1. 


\section{INTRODUCTION}

In recent years, autoimmune epilepsies with antibodies against various antigens have been described. Among these are cases with antibodies targeting surface receptors such as the $N$-methyl-Daspartate receptor (1), the $\alpha$-amino-3-hydroxy-5-methyl-4isoxazolepropionic acid receptor (2), the $\gamma$-aminobutyric acid-B receptor $\left(G A B A_{B} R\right)(3)$, or the voltage-gated potassium channel (VGKC) complex (4). For the latter, it is now known that, in most cases, the antibodies are directed to leucine-rich glioma inactivated protein 1 (LGI1) $(5,6)$. Patients with LGI1 antibodies typically develop limbic encephalitis and suffer from amnesia, confusion, personality change or psychosis, seizures, and often hyponatremia $(7,8)$.

In human LGI1 encephalitis, magnetic resonance imaging (MRI) studies have shown increased volume and T2 signal of temporomesial structures with the hippocampus most prominently affected. Initial swelling of these structures is often followed by atrophy $(8,9)$. Whereas seizures, amnesia, and confusion likely result from autoantibody-mediated inflammation and lesions in the hippocampus (10), the neuropsychiatric symptoms, such as personality changes, psychosis or mood disorders, can be explained by the involvement of the amygdala, which is known for its key role in processing emotions and behavior (11-14).

The involvement of the hippocampus in human LGI1 encephalitis has been confirmed in histopathological studies. Parenchymal $\mathrm{T}$ cell infiltrates are present, but sparse. In addition, neurodegeneration caused by immunoglobulin $\mathrm{G}$ and complement deposition has been shown $(15,16)$. Two different pathogenic mechanisms may play a role in the action of LGI1 antibodies. First, the LGI1 antibodies seem to bind to LGI1, resulting in a functional change in LGI1, which can be reversed as steroids and plasma exchange swiftly ameliorate the disease symptoms (8, 17). Second, complement-mediated neuronal destruction occurring in the hippocampus may contribute to temporomesial atrophy and persisting cognitive deficits in nearly all patients, despite treatment options $(9,11,15)$.

Recently, we described an acute seizure disorder with orofacial involvement in cats. This disorder was coined feline complex partial seizures with orofacial involvement (FEPSO) (18). Besides the distinct clinical features, these cats in MRI scans showed bilateral hippocampal T2 signal increase. Importantly, cell-based assays revealed that almost all tested sera of these cats contained anti-LGI1 antibodies (16, 18-20). Subsequent analysis of the hippocampus of these animals revealed the presence of inflammatory T cells, B cells, and plasma cells in the parenchyma. Moreover, neurodegeneration in these animals was caused by immunoglobulin and complement deposition (16). Overall, clinical, neuropathological and MRI analysis, therefore, indicate that FEPSO is the feline equivalent of human LGI1 encephalitis and might be used as a natural model for this disease.

In both human LGI1 encephalitis and in FEPSO, little is known about pathologic changes outside the hippocampus. Extrahippocampal pathology is expected since human LGI1 antibody-positive sera not only bind to the hippocampus but also to other regions, including the molecular layer of the cerebellum where LGI1 is expressed in high amounts $(6,21,22)$. Nevertheless, in human patients, cerebellar features such as ataxia have been found much less frequently than limbic affection $(23,24)$. MRI studies in LGI1 encephalitis have shown T2 signal increase and sclerosis of the whole mesial temporal lobe $(6,8)$ but also in the basal ganglia, which are thought to contribute to faciobrachial dystonic seizures (25-27). Less frequently, white matter atrophy (28) and blurring, suggestive of mild de- or hypomyelination, was shown (29).

Taken together, although the limbic system displays the most frequent and most prominent signs and symptoms, recent publications point toward the involvement of other brain areas. The limited amount of human material, especially of brain structures other than the impaired hippocampus, poses a problem in the study of these extrahippocampal structures.

Since a relatively high number of FEPSO brains are available, we took the opportunity to perform a detailed neuropathological analysis of limbic and non-limbic structures. Our analysis shows that inflammatory infiltrates can be found brain-wide. A disturbance of the blood-brain barrier (BBB), occurring with prominent loss of tight junctions and resulting in leakage of immunoglobulin and complement, however, was more restricted. This leakage was found in brain areas such as the hippocampus but also in the subiculum, amygdale, and piriform lobe and, to a lesser degree, in the basal ganglia and hypothalamus. Moreover, in these areas, immunoglobulin and complement deposition to neurons was present and was associated with severe neurodegeneration. Importantly, this finding suggests that $\mathrm{BBB}$ disturbance and immunoglobulin leakage does not depend on $\mathrm{T}$ cell inflammation but that other, yet unknown, mechanisms are responsible.

\section{MATERIALS AND METHODS}

\section{Animals}

In this study, 16 cats with FEPSO, characterized by facial seizures and hippocampal sclerosis or hippocampal necrosis (18), were included. Five of these cats were tested positive for serum antibodies against VGKC complex and showed positive reactivity to LGI1 in a cell-based binding assay as shown previously (16). The remaining 11 cats showed seizures typical of FEPSO but could not be tested for LGI1-reactive antibodies due to absence of sera. Throughout the manuscript, the definitive LGI1 antibody-positive FEPSO animals are indicated and separated from the FEPSO animals with unknown LGI1 antibody status. LGI1-positive animals are indicated in red and untested animals in black dots in all graphs. Of the 16 animals, 2 died spontaneously; all others were euthanized due to resistance to therapy or severe clinical course between 2 days and 34 months after onset of neurological signs. One cat (case 1) had papillary adenomas, whereas in the other cats, no tumors were found. Cats received antiepileptic therapy with phenobarbital, gabapentin, levetiracetam, potassium bromide, or a combination of those. Additionally, five cats were treated with prednisolone $1-2 \mathrm{mg} / \mathrm{kg}$ twice daily. For an epileptic control group, seven cats with epileptic seizures not fitting the classification of FEPSO (18) were used. Five suffered from temporal lobe epilepsy, four of which also had HS, one cat had an edema, and 
one a meningioma. Additionally, seven cats without neurological implication, which died as a result of other, non-neurological problems, were selected for the normal control group. For animal details, please refer to Table S1 in Supplementary Material.

\section{Ethics Approval}

The project was discussed and approved by the institutional ethics committee (University of Veterinary Medicine, Vienna) in accordance with GSP guidelines and national legislation.

\section{Neuropathology and Immunohistochemistry}

In all cats, a general necropsy was performed, and brains were fixed in $4 \%$ neutral-buffered formalin, embedded in paraffin, and coronal sectioned. Immunohistochemistry was performed as shown previously (15) at the level of the frontal cortex, nucleus accumbens, amygdala, hippocampus, and cerebellum. Luxol Fast Blue-Periodic Acid Schiff staining was performed to study changes (demyelination or hypomyelination) in white matter. Immunohistochemistry was performed with antibodies for T lymphocytes (anti-CD3), endothelial cells [transglutaminase 2 (TG2)], early constituents of the complement cascade (C1q), fully assembled complement system end complex (C9neo), feline immunoglobulin, and neurons [neuronal nuclei (NeuN)], and myelin-associated protein 2 (MAP-2). Antigen retrieval was done by heating the sections for $45 \mathrm{~min}$ in EDTA $(0.05 \mathrm{M})$ in tris(hydroxymethyl)aminomethane (Tris) buffer $(0.01 \mathrm{M}, \mathrm{pH}$ $8.5)$ or citrate buffer (0.01 M, pH 6) in a household food steamer device for all antibodies except for $\mathrm{C} 9$ neo, and immunoglobulin, in which case antigen retrieval was performed by incubating the tissue for $15 \mathrm{~min}$ in proteinase (bacterial proteinase Type XXIV, \#SLBQ7212V, Sigma Life Science) at $37^{\circ} \mathrm{C}$. For more detailed information regarding antibodies, dilutions used, and antigen retrieval, please refer to Table S2 in Supplementary Material.

\section{Fluorescent Immunohistochemistry}

We investigated $\mathrm{BBB}$ damage in more detail by double-labeling for the tight junction marker zona occludens 1 (ZO-1) and cat immunoglobulin in FEPSO animals in the hippocampus, the amygdala, basal ganglia, cortex, and cerebellum. Additionally, we investigated the hippocampus in normal and epileptic controls. Cats showing an average degree of BBB leakage were selected and investigated. To check for endothelial cell integrity of the blood vessels, we performed a triple staining for ZO-1, cat immunoglobulin, and von Willebrand Factor (vWF) as endothelial marker. Antigen retrieval was done with proteinase for $15 \mathrm{~min}$ at $37^{\circ} \mathrm{C}$, and standard staining procedures were followed as described previously (15). For more detailed information regarding antibodies, dilutions used, and antigen retrieval, please refer to Table S2 in Supplementary Material.

\section{Terminal Deoxynucleotidyl Transferase dUTP Nick End Labeling}

Qualitative assessment of chronic cell loss was conducted in stained coronal sections at the level of the frontal cortex, basal ganglia, amygdala, hippocampus, and cerebellum. For the detection of cells with DNA fragmentation, TUNEL staining was performed with the In Situ Cell Death Detection Kit ${ }^{\circledR}$ (Roche, Basel, Switzerland) as described elsewhere (15) and developed with Fast Blue. To identify dying neurons, this step was followed by immunohistochemical staining for MAP-2 or NeuN, which was developed with 3-amino-9-ethylcarbazole as a substrate.

\section{Quantification of Cells}

$\mathrm{CD}^{+}$cells were quantified by light microscopy using a morphometric grid in $1.25 \mathrm{~mm}^{2}$ (20 grids in $400 \times$ magnification) or $2.5 \mathrm{~mm}^{2}$ (40 grids in $400 \times$ magnification), depending on the number of brain slices containing the region of interest. C9neo ${ }^{+}$ cells were counted in $1.25 \mathrm{~mm}^{2}$ ( 20 grids in $400 \times$ magnification) for the cortex, cerebellum, and caudate nucleus. In the amygdala and the hippocampus, $\mathrm{C}$ neo $^{+}$cells were counted in the whole area. For the determination of cell loss, the number of $\mathrm{TUNEL}^{+}$ cells among 100 cells was determined in the respective areas. For the determination of neuronal loss in the hippocampus, the number of $\mathrm{NeuN}^{+}$cells was counted in $0.75 \mathrm{~mm}^{2}$ (3 grids in $200 \times$ magnification) of each hippocampal subfield in normal controls and FEPSO cats. The percentage of remaining $\mathrm{NeuN}^{+}$ cells in comparison with normal controls was calculated for each subfield. The statistical difference to $100 \%$ (equal to "no neuronal loss") was calculated.

\section{Quantification of Immunoglobulin}

For quantification of immunoglobulin in different brain areas as well as in the hippocampus between FEPSO and controls, all slides were incubated and developed for the final color reaction for the exact same time. Images were analyzed using Image by digital optical densitometry, as shown previously (30).

\section{Magnetic Resonance Imaging}

MR studies of two cats, acquired with a high-field MR unit (Magnetom Espree, 1.5T, Siemens Healthcare, Erlangen, Germany), were retrospectively evaluated. In each case, transverse T2-weighted fluid attenuation inversion recovery (FLAIR), sagittal 3D T2-weighted turbo spin echo (T2), transverse 2D and sagittal 3D pre- (T1) and post-contrast T1-weighted turbo spin echo images (T1C) were available. Slice thickness was $0.8-3 \mathrm{~mm}$.

\section{Graphical Presentation of Inflammation, Neurodegeneration, and Complement Deposition}

For a full overview on neuropathological changes, a brain-wide investigation for inflammation, neurodegeneration, and complement deposition was performed. Graphical representations of coronal cat brain slices containing the hippocampus, amygdala, cortex, basal ganglia, and cerebellum, were produced with CorelDRAW X4 based on images present on www.brainmaps.org (31). Infiltrates, neurodegeneration, and complement deposition in 16 cats with FEPSO were drawn into the cat brain images using Adobe Photoshop CS4.

\section{Statistical Analysis}

For statistical analysis, GraphPad Prism 6 was used. First, we tested for differences between FEPSO animals positive for 
LGI1 antibodies and FEPSO animals with unknown LGI1 antibody status. To this end, a two-way ANOVA was used, but no differences were found. Therefore, datasets were pooled for further analysis, which was performed with Kruskal-Wallis tests with Dunn's correction for multiple testing. Neuronal loss within the hippocampus was evaluated by the percentage of remaining neurons with regard to normal control hippocampal subareas (corresponding to $100 \% \mathrm{NeuN}^{+}$cells). To this end, a Wilcoxon-signed rank test was performed. All graphical data are represented as medians with the interquartile ranges. Animals tested positive for LGI1 antibodies and animals with unknown status are graphically separated (data points and error bars). Data of LGI1 antibody positive animals indicated in red and animals with unknown status indicated in black. Results were considered statistically significant at $p \leq 0.05$.

\section{RESULTS}

\section{Inflammation}

In the hippocampus of normal controls, parenchymal inflammatory $\mathrm{T}$ lymphocytes were very rare $\left(1.2 \mathrm{cells} / \mathrm{mm}^{2}\right)$. The hippocampus of epileptic controls showed higher numbers of $\mathrm{T}$ cells $\left(2.4\right.$ cells $\left./ \mathrm{mm}^{2}\right)$. These $\mathrm{T}$ cell numbers were comparable to $\mathrm{T}$ cell numbers in hippocampi of FEPSO animals (3.2 cells/ $\mathrm{mm}^{2}$ ). Statistical analysis of hippocampal $\mathrm{T}$ cell numbers between normal controls, epileptic controls, and FEPSO, possibly due to the high variance, however, revealed no significant difference. In brains of FEPSO animals, T cells were mostly found in perivascular cuffs and the meninges, with only moderate parenchymal infiltrating $\mathrm{T}$ cells. Parenchymal $\mathrm{CD}^{+} \mathrm{T}$ cells were found in all investigated regions of the brain, including the hippocampus, amygdala, basal ganglia, cortex, and cerebellum (Figures 1A-E and 6). T cell infiltrates, besides in gray matter, also were found in white matter tracts (Figure 1F). To determine if brain regions with high LGI1 abundance, such as the cerebellum or the hippocampus, showed increased levels of $\mathrm{T}$ cells, we quantified the number of $\mathrm{CD}^{+} \mathrm{T}$ cells in these different regions. However, no significant difference in cell number was found (Figure 1G).

\section{BBB Leakage}

Immunoglobulin leakage was not found in the parenchyma of normal controls (Figure 2A). Epileptic controls, on the other hand, showed slightly increased levels of parenchymal immunoglobulin in the hippocampus and, to a lesser extent, in the cortex (Figure 2B). In FEPSO brains, leakage of immunoglobulin over the $\mathrm{BBB}$ was prominent in all limbic structures (Figures $\mathbf{2 C - F}$ ). Most prominently affected were several nuclei of the amygdala, namely, the lateral and medial basal amygdala ( $\mathrm{N}$. basalis), the lateral (N. lateralis), medial (N. medialis) and central (N. centralis) amygdala, periamygdaloid area, and anterior cortical nucleus of the amygdala (N. corticalis) (Figure 2D), as well as, bilaterally, the hippocampus, adjacent subiculum, and entorhinal cortex (Figure 2E). These regions overlapped with signal and volume increase found in MR imaging (Figure 2G). In some animals, immunoglobulin leakage was also observed in the prepiriform cortex, putamen, claustrum, olfactory tubercle, nucleus accumbens, tenia tecta, septo-olfactory junction, hypothalamus, and anterior commissure (Figure 6). In the cerebellum, no significant immunoglobulin leakage was found (Figure 2F). Quantification of the mean optical density of immunoglobulin in the hippocampi confirmed the absence of immunoglobulin leakage of normal control cats. FEPSO cats showed a significant increase of immunoglobulin leakage compared to the baseline of normal controls (median of $70 \%$ increase). When compared with epileptic controls, no significant difference was found (Figure $2 \mathbf{H}$ ). Within FEPSO animals, different brain areas showed large differences in immunoglobulin abundance. The amount of immunoglobulin in the hippocampus was significantly elevated compared to that in the basal ganglia, cortex, and cerebellum. Interestingly, we found no significant difference between the hippocampus and the

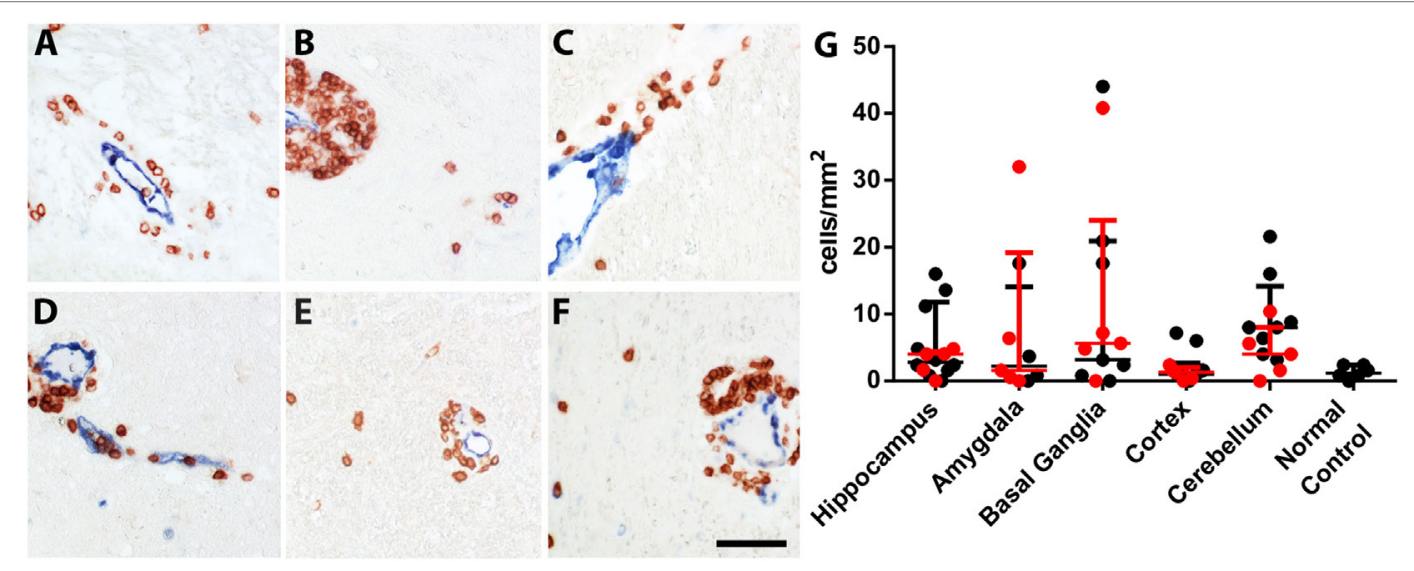

FIGURE 1 | Inflammatory infiltrates in FEPSO can be found all over the brain in gray and white matter. Immunohistochemical staining for CD3 ${ }^{+}$and transglutaminase 2 showed that $\mathrm{T}$ cells are mainly located in perivascular cuffs with moderate parenchymal infiltrates in all inspected areas, namely the (A) hippocampus, (B) amygdala, (C) basal ganglia, (D) cortex, (E) cerebellum, and (F) white matter. (G) Quantification of parenchymal T cell infiltrates in the abovementioned areas did not reveal differences in T cell densities. Data shown as median with interquartile range, LGl1 antibody-positive animals are indicated in red and untested animals in black; (ns $p>0.05$ Kruskal-Wallis test with Dunn's post hoc correction, hippocampus $n=15$, amygdala $n=9$, basal ganglia $n=12$, cortex $n=15$, cerebellum $n=13$, normal controls $n=6$ ) Scale bar corresponds to $50 \mu \mathrm{m}$. 

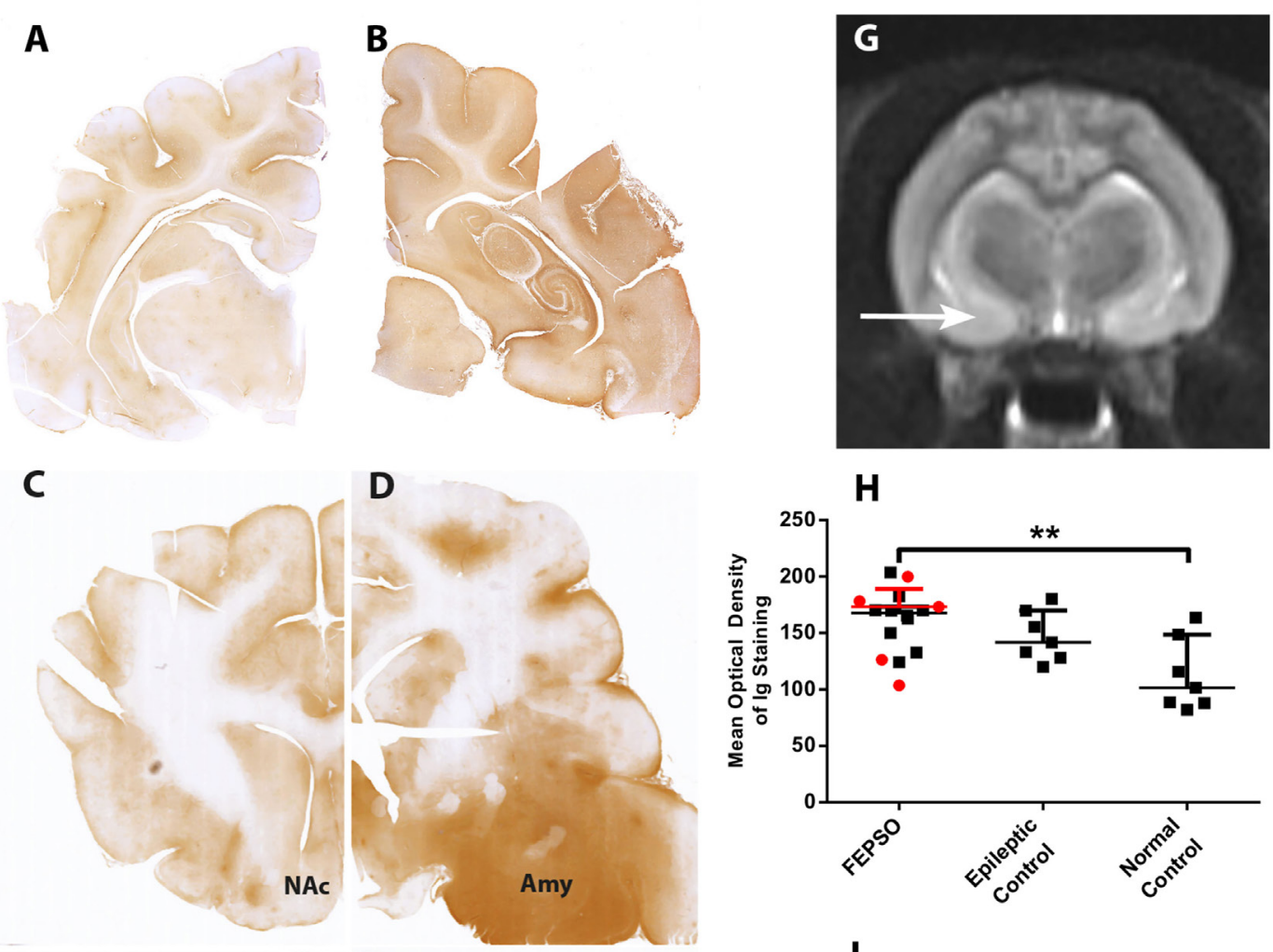

H
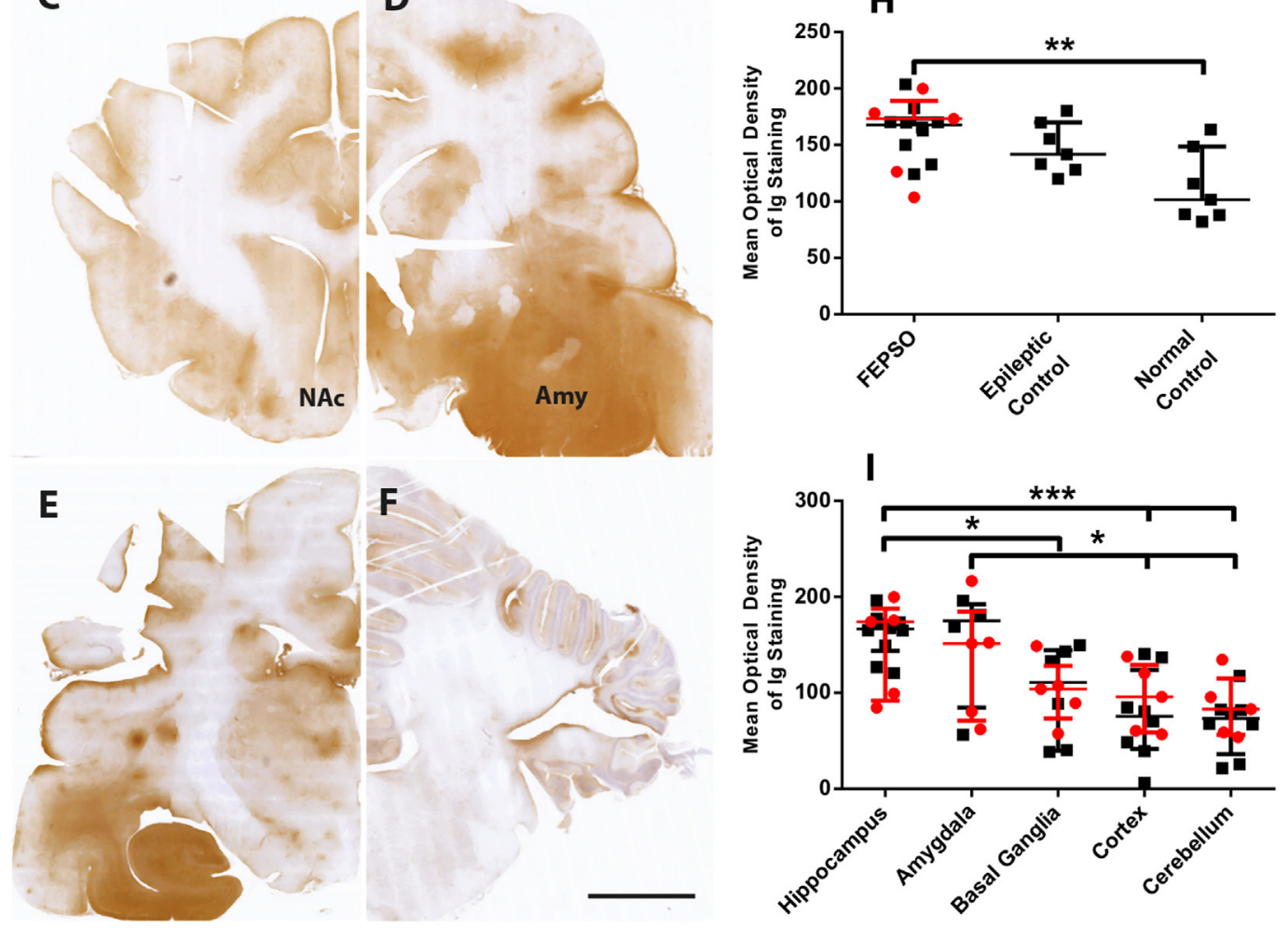

FIGURE 2 | Selective blood-brain barrier leakage overlaps with MR signal changes in the amygdala. (A-F) Staining for immunoglobulin in representative images of coronal brain sections in (A) normal controls, (B) epileptic controls, and in FEPSO at the level of (C) frontal cortex and nucleus accumbens, (D) amygdala and piriform lobe, (E) hippocampus, and (F) cerebellum. Immunoglobulin leakage is seen prominently in the hippocampus but also in the amygdala and adjacent regions. Scale bar corresponds to $5 \mathrm{~mm}$. (G) Transverse T2-weighted MR image at the level of the hippocampus and piriform lobe in a 1-year-old female neutered European shorthair cat, orientated along the long axis of the hippocampus on a sagittal slice. The MR signal is bilaterally abnormally increased, and the area of the amygdala (arrow) appears bilaterally enlarged. (H) Optical density quantification of lg leakage in FEPSO, epileptic, and normal control hippocampus. The hippocampi of FEPSO have higher values than normal controls. Data shown as median with interquartile range, LGI1 antibody-positive animals, are indicated in red and untested animals in black ( ${ }^{\star \star} p<0.01$, Kruskal-Wallis test with Dunn's post hoc correction, FEPSO $n=15$, epileptic controls $n=7$, normal controls $n=7$ ). (I) Significant elevation of immunoglobulin signal in hippocampus and amygdala in FEPSO cats compared to other brain areas of the same cats. LGl1 antibody-positive animals are indicated in red and untested animals in black. Data shown as median with interquartile range $\left(^{*} p<0.05\right.$, ${ }^{* \star *} p<0.001 ;$ Kruskal-Wallis test with Dunn's post hoc correction, hippocampus $n=15$, amygdala $n=9$, basal ganglia $n=12$, cortex $n=15$, cerebellum $n=13$ ).

amygdala, indicating comparable leakage in both areas. Moreover, the amount of immunoglobulin in the amygdala was significantly elevated compared with the cortex and the cerebellum (Figure 2I). We could not detect a significant difference in immunoglobulin signal intensities between hippocampal subareas.

\section{Magnetic Resonance Imaging}

Because our study revealed pathological changes outside the hippocampus, especially in the amygdala, we analyzed MRIs from two FEPSO brains (\#2 and \#15) to support our findings. Bilateral $\mathrm{T} 2$-weighted signal and volume increase changes were found in 
the hippocampus as well as at the level of the amygdala and the piriform lobe (Figure 2G).

\section{Tight Junction Breakdown in Blood Vessels}

Blood-brain barrier disruption might be associated with a loss of tight junctions. We, therefore, decided to investigate these structures in our animals. In control animals, the tight junction marker ZO-1 was strongly expressed around vessels. When viewed in longitudinal sections of capillaries, a continuous staining could be observed. Double labeling with Ig showed that, in such vessels, no leakage was observed and Ig was only seen on the luminal side of the vessel (Figure 3A). Under pathological conditions, in the hippocampus of epileptic controls, ZO-1 reactivity was weaker and discontinuous. Here, moderate immunoglobulin leakage could be observed in the surrounding brain parenchyma (Figure 3B). In the hippocampus of FEPSO animals, we observed a drastic decrease in ZO-1 reactivity. Here, ZO-1 immunoreactivity was very weak and visible in small patches instead of showing a continuous staining pattern. Furthermore, this loss of ZO-1 was associated with severe immunoglobulin leakage in the surrounding parenchyma (Figure 3C). The ZO-1 reactivity in the amygdala was comparable to what was seen in the hippocampus, with severe loss of ZO-1 intensity and loss of integrity. Additionally, also in the amygdala, strong immunoglobulin immunoreactivity was observed in the parenchyma, showing similar BBB breakdown and leakage as in the hippocampus (Figure 3D). This was different in basal ganglia (Figure 3E), cortex (Figure 3F), and cerebellum (Figure 3G) of FEPSO animals where ZO-1 reactivity was strong and in a regular continuous staining pattern. Immunoglobulin in these regions again was restricted to the lumen of the vessels, and Ig leakage in the parenchyma could not be found. To indicate the endothelial lining of the blood vessels, vWF was added in the merged images.

\section{Immunoglobulin and Complement Deposition}

Normal control animals did not show any immunoglobulin deposition on neurons and epileptic controls showed immunoglobulin deposition in some cats. In FEPSO cats, brain areas with $\mathrm{BBB}$ leakage revealed strong membranous immunoglobulin deposition on severely damaged neurons. This was found in all limbic structures but was especially prominent in the hippocampus, (pre-) subiculum, entorhinal cortex, and amygdala. In some animals, immunoglobulin deposition was observed in the prepiriform cortex, putamen, claustrum, olfactory tubercle, nucleus accumbens, tenia tecta, septo-olfactory junction, hypothalamus, and anterior commissure. amygdala.

In order to analyze early constituents of the complement cascade, we stained for complement factor C1q. In normal controls, C1q was occasionally found on the surface of cortical neurons. However, in none of these animals, Clq was found on neurons in the hippocampus (Figure 4A). A similar staining pattern was observed in epileptic controls (Figure 4B). In FEPSO animals, besides on the surface of some cortical neurons, Clq was mostly present on the surface of hippocampal neurons while single neurons in addition showed granular staining in the cytoplasm (Figure 4C).

Complement activation, indicated by the complement end complex marker C9neo, was not seen in normal controls. In epileptic controls, although immunoglobulin deposition was observed in some of these brains, C9neo reactivity was completely absent. In cats with FEPSO, regions with Ig deposition also showed complement $\mathrm{C} 9$ neo immunoreactivity in a punctate appearance on the membrane as well as inside of neurons. This was most prominently seen in the hippocampus (Figures $4 \mathrm{D}, \mathbf{G}$ ) and in the amygdala (Figures 4E,H). Neither in the basal ganglia nor in the cerebellum were $\mathrm{C} 9 \mathrm{neo}^{+}$cells found (Figures $4 \mathrm{~F}, \mathrm{~J}$ ). Besides the entorhinal and prepiriform cortex, no complement deposition could be detected in the cortex (Figure 4I). Also, the white matter did not show any sign of complement activation (Figure 4K). In some animals, neurons with complement deposition were present in the dorsal hypothalamic area, tenia tecta, anterior prepiriform cortex, putamen, olfactory tubercle, and anterior commissure (Figure 6). Quantitative analysis of the number of $\mathrm{C}$ neo $^{+}$neurons revealed that complement deposition was significantly elevated in the hippocampus and amygdala compared to other brain areas such as basal ganglia, cortex, and cerebellum (Figure 4L).

\section{Neurodegeneration and Neuronal Cell Loss}

None of the normal control animals showed neuronal loss. Epileptic control animals, however, showed variable neuronal loss in the hippocampus and subiculum. In FEPSO animals, regions showing neurodegeneration largely correlated with immunoglobulin and C9neo deposition and were found in both hemispheresin thelimbicstructures (Figure6). The hippocampus and the subiculum showed high numbers of TUNEL ${ }^{+}$cells, indicating a high degree of cell death (Figures 5A,B). Additionally, we found $\mathrm{TUNEL}^{+}$cells in the amygdala (Figures $5 \mathrm{C}, \mathrm{D}$ ). The affected areas comprised the lateral and medial basal amygdala (N. basalis), the lateral (N. lateralis), medial (N. medialis) and central (N. centralis) amygdala, periamygdaloid area, and anterior cortical nucleus of the amygdala ( $\mathrm{N}$. corticalis). In single animals, we also found neuronal loss and some TUNEL ${ }^{+}$cells in the tenia tecta, septo-olfactory junction, entorhinal cortex, anterior commissure, nucleus accumbens, claustrum, or the posterior prepiriform area (Figure 6). In none of the FEPSO animals was neurodegeneration observed in the cortex (except the entorhinal cortex, see above) or cerebellum (Figures 5E-G). Moreover, the white matter did not show any sign of hypo- or demyelination (Figure 5H). Quantification of the number of $\mathrm{TUNEL}^{+}$cells showed a significant increase of cell death in the hippocampus compared with the amygdala, basal ganglia, cortex, and cerebellum (Figure 5I).

Additionally, we questioned whether hippocampal subfields were equally affected. Quantification of neurons in these subfields in normal controls and FEPSO showed that CA4 was the most severely affected (median cell loss of $78.3 \%$ ). In CA1, $52.2 \%$ were lost, and in CA2 and CA3, 37.5 and $46.7 \%$ were lost, respectively. The dentate gyrus, with a median of $98.2 \%$ remaining neurons, did not show significant neuronal loss, although three FEPSO 

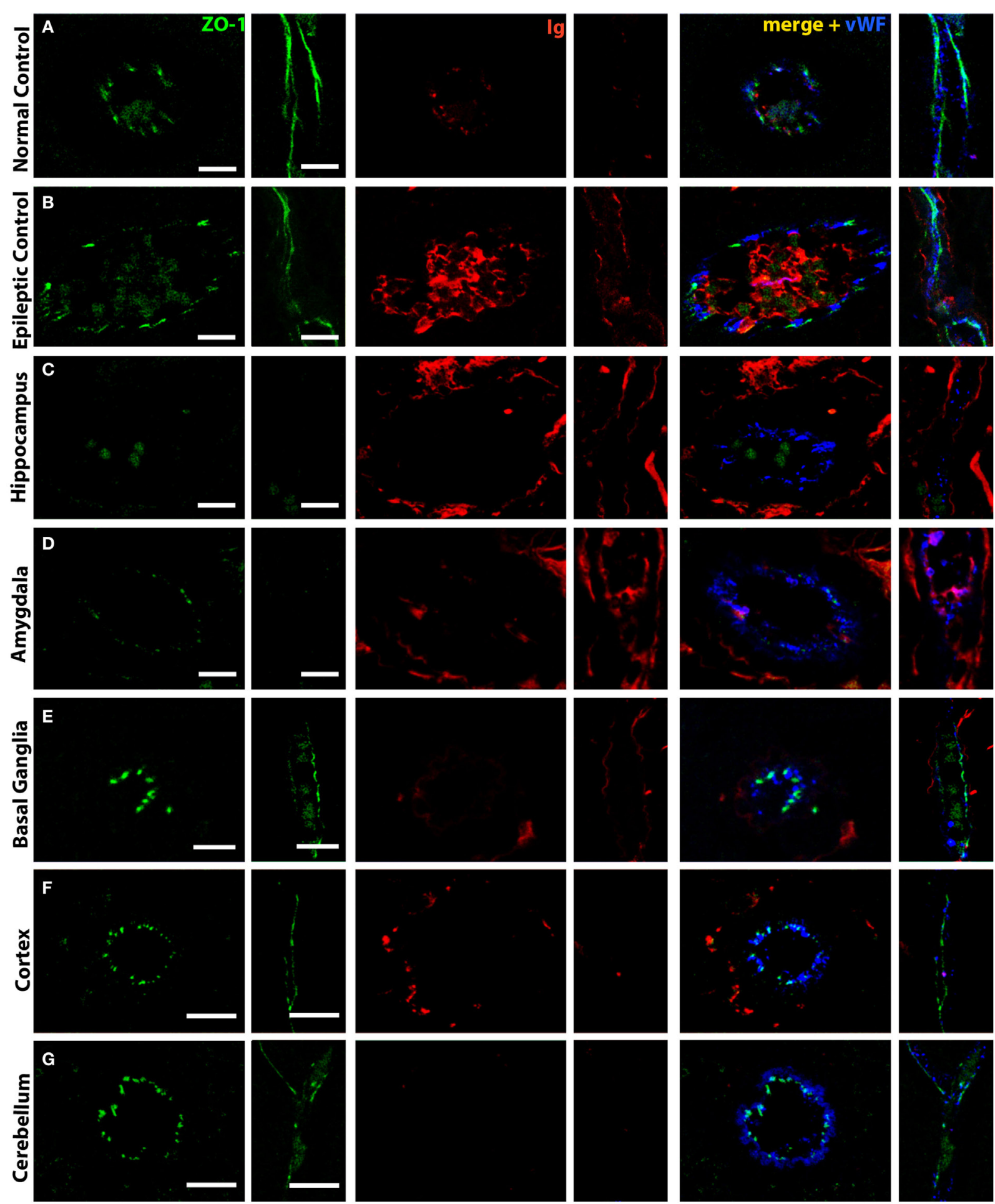

FIGURE 3 | Selective tight junction breakdown leads to blood-brain barrier leakage. Staining of tight junctions [zona occludens 1 (ZO-1), green], immunoglobulin (red), and von Willebrand Factor (blue) in (A) normal controls, (B) epileptic controls, and (C-G) FEPSO cats positive for LGl1 antibodies. The tight junction protein ZO-1 is found between endothelial cells in a strong and (in longitudinal cuts) continuous staining in (A) normal controls in the hippocampus. Therefore, weak immunoglobulin staining is restricted to the luminal side of the blood vessels. (B) In hippocampi of epileptic controls, the ZO-1 staining is weaker, less continuous, and associated with some immunoglobulin reactivity in the parenchyma. (C) In FEPSO, blood vessels in the hippocampus have very weak and discontinuous ZO-1 signal, indicating tight junction breakdown. Here, immunoglobulin has clearly leaked into the parenchyma. (D) In the amygdala, the same pattern of tight junction breakdown was seen, indicated by a weak and discontinuous ZO-1 staining, and immunoglobulin leakage into the parenchyma. In all other investigated brain areas such as (E) basal ganglia, (F) cortex, and (G) cerebellum, in FEPSO cats, no ZO-1 breakdown was observed and immunoglobulin only was found on the luminal side of the vessels or perivascular space. Scale bars correspond to $10 \mu \mathrm{m}$ (A-D,F,G) or $5 \mu \mathrm{m}$ (E) 


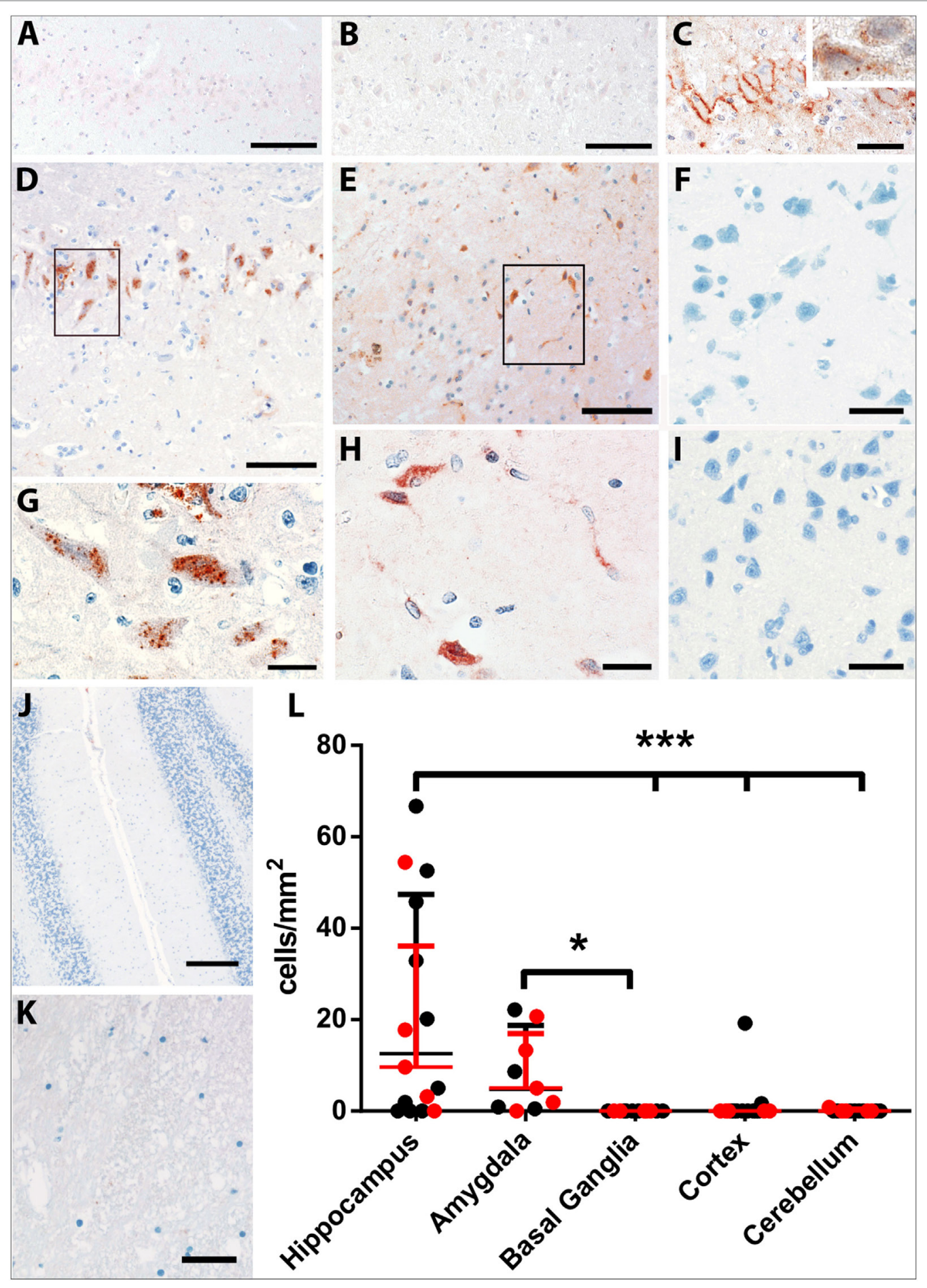

FIGURE 4 | Complement deposition in LGl1 antibody-positive FEPSO animals. Staining for early constituent, C1q of the complement cascade shows the absence of C1q on neurons of (A) the hippocampus of a normal control and (B) the hippocampus of an epileptic control animal. (C) The hippocampus of a FEPSO cat shows C1q reactivity on the surface of hippocampal neurons with occasional granular staining inside the cells (inset). (D-K) The brain areas affected by BBB leakage are also affected by complement activation as shown by immunohistochemistry for C9neo. (D) In the hippocampus, complement-positive cells are visible, which show a $[(\mathbf{G})$, enlargement] granular staining pattern inside the cells. (E) The amygdala shows very similar staining with C9neo positive cells, which $[(\mathbf{H})$, enlargement] show the same granular staining inside the cells. Neither (F) the basal ganglia, (I) cortex, (J) cerebellum nor (K) white matter showed any complement positive cells or structures. (L) Quantification of C9neo positive cells revealed significantly higher numbers in the hippocampus as well as in the amygdala. Data shown as median with interquartile range, LGl1 antibody-positive animals are indicated in red, and untested animals in black ( ${ }^{*} p<0.05$, Kruskal-Wallis test with Dunn's post hoc correction, hippocampus $n=15$, amygdala $n=9$, basal ganglia $n=12$, cortex $n=15$, cerebellum $n=13$ ). Scale bars correspond to (A,B,D,E) $100 \mu \mathrm{m}, \mathbf{( C )} 50 \mu \mathrm{m}, \mathbf{( G , H )} 20 \mu \mathrm{m}, \mathbf{( F , I , K )} 25 \mu \mathrm{m}$, and (J) $200 \mu \mathrm{m}$. 

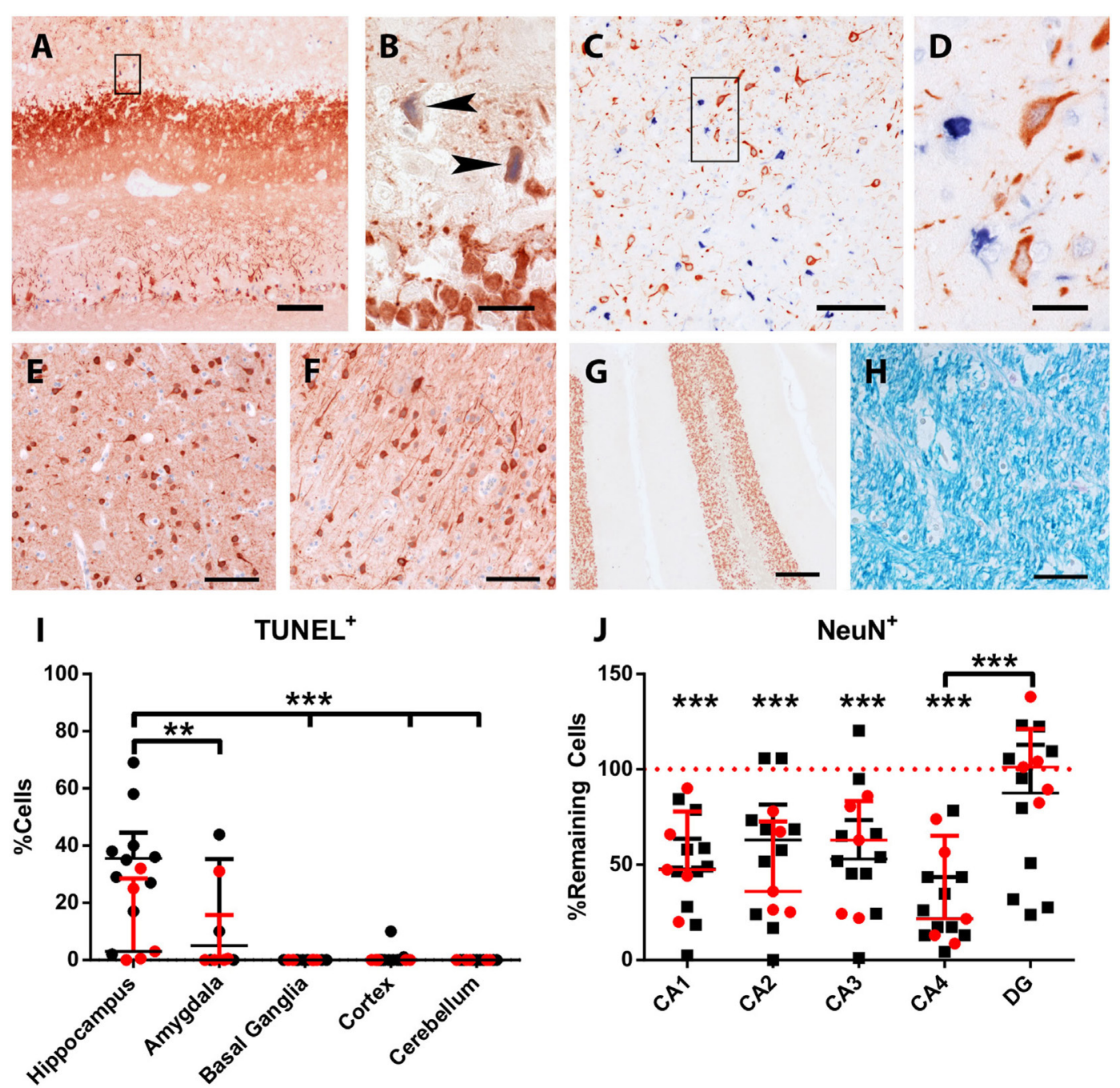

FIGURE 5 | Acute neuronal degeneration and cell loss in LGI1 antibody-positive FEPSO animals. Staining for terminal deoxynucleotidyl transferase dUTP nick end labeling (TUNEL) (blue) and MAP2/neuronal nuclei (NeuN) (red). (A) TUNEL ${ }^{+}$cells and severe loss of neurons and processes is visible in the hippocampus. (B) Shows the areas indicated by the rectangle in Figure 5A, revealing TUNEL+ neurons and loss of myelin-associated protein 2 reactivity (arrowheads). (C) In the amygdala, a high number of TUNEL+ nuclei are visible, while in (D), enlargement of rectangle in Figure $\mathbf{5 C}$ and loss of MAP2-reactivity around

TUNEL + nuclei is observed. Neither in the $(\mathbf{E})$ basal ganglia, $\mathbf{( F )}$ cortex, $(\mathbf{G})$ cerebellum nor $\mathbf{( H )}$ white matter TUNEL+ cells or de-hypomyelination was observed. (I) The percentage of TUNEL ${ }^{+}$cells in different areas was quantified. This graph shows significant cell loss in the hippocampus of FEPSO animals. Data are shown as median with interquartile range, LGl1 antibody-positive animals are indicated in red, and untested animals in black ( ${ }^{\star \star \star} p<0.001$, Kruskal-Wallis test with Dunn's post hoc correction, hippocampus $n=15$, amygdala $n=9$, basal ganglia $n=12$, cortex $n=15$, cerebellum $n=13)$. (J) Hippocampal cornu ammonis (CA) subfields revealed severe loss of NeuN-positive cells compared with normal controls (equals 100\%) in CA1-4, but not in DG. CA4 subfields exhibits reveal the most severe cell losses, which was significantly different from the loss in the DG. Data shown as median with interquartile range $\left({ }^{\star * *} p<0.001\right.$, Wilcoxon signed-rank test with hypothetical value: $100, n=14,{ }^{* *} p<0.01$, Kruskal-Wallis test with Dunn's post hoc correction for evaluation of inter-hippocampal differences, $n=14)$. Scale bar corresponds to (A) $200 \mu \mathrm{m}, \mathbf{( B , D )} 20 \mu \mathrm{m}$, (C) $100 \mu \mathrm{m}, \mathbf{( E , F , H )} 50 \mu \mathrm{m}$, and (G) $200 \mu \mathrm{m}$.

animals also showed severe neurodegeneration in the dentate gyrus with less than $50 \%$ of neurons remaining. Finally, CA4 showed significant neuronal loss compared with the dentate gyrus (Figure 5J). This neuronal loss in FEPSO corresponds to human hippocampus sclerosis type 1 according to the classification of the international league against epilepsy (32). One recent MRI study on human LGI1 encephalitis found volume loss in CA3 only (33), whereas another one found all areas except CA1 to be affected (9). These intrahippocampal differences, however, cannot be explained by differential expression of LGI1, as, at least in mice, it is most prominently expressed in CA3 and the dentate gyrus (22), and these two subareas in FEPSO strongly differ in the amount of neurodegeneration.

\section{DISCUSSION}

LGI1 encephalitis is a form of autoimmune epilepsy, an expanding group of disorders with antibodies against various neural 


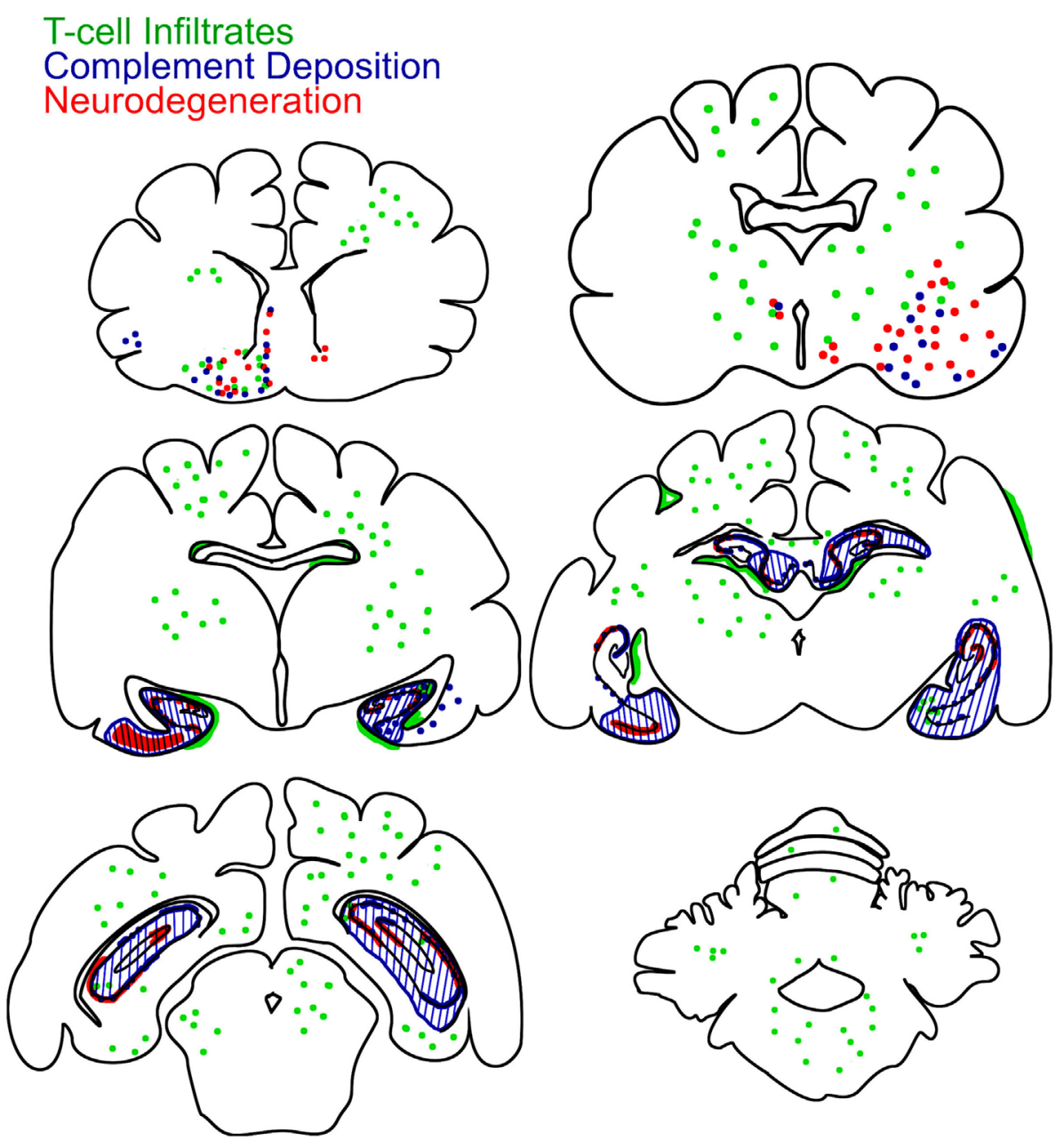

FIGURE 6 | Brain-wide mapping of pathological changes in FEPSO. Cumulative graphical presentation of T cell infiltrates (green), neurodegeneration (red), and complement deposition (blue) in the brains of 16 cats suffering from FEPSO. This presentation shows that inflammatory lesions are brain-wide. Neurodegeneration and complement deposition show strong overlap and is most prominent in the hippocampus, amygdale, and adjacent areas.

antigens and epileptic seizures as one of the broad range of neurological signs. The similarities between human LGI1 encephalitis and FEPSO have only recently been discovered $(16,20)$. These similarities comprise not only the presence of antibodies against LGI1 and the pathological changes seen in the hippocampus but also clinical symptoms such as radiological changes and facial seizures $(15,16)$.

The findings that human LGI1-positive sera show strong staining of the cerebellum and that human patients can (very rarely) develop cerebellar symptoms $(24,34)$ and the MRI studies that show involvement of the amygdala $(35,36)$ and basal ganglia (25-27) piqued our interest to investigate pathological changes in brain structures other than the hippocampus. Here, we show that inflammatory infiltrates are not restricted to the hippocampus but are also found in most other parts of the brain. Since inflammatory lesions do not overlap with areas affected by neurodegeneration, it can be assumed that $\mathrm{T}$ cells do not directly contribute to cell death. Interestingly, in human VGKC-limbic encephalitis, T cell infiltrates have also been found in the amygdala and the uncus in similar numbers as in FEPSO (15). The number of these infiltrating $\mathrm{T}$ cells is much lower than those found in $\mathrm{T}$ cell-mediated neurodegeneration, such as in paraneoplastic encephalitis in humans (15). In line with our results, a human MRI study found brain-wide metabolic changes, in gray as well as white matter, pointing toward brain-wide neuroinflammation (28). Here, we also found prominent $\mathrm{T}$ cell infiltrates in the white matter. This might explain the recently reported supratentorial white-matter blurring in MRI scans of human LGI1 encephalitis brains (29), since myelin breakdown and inflammatory infiltrates leading to localized edema can be difficult to distinguish in MRI scans (37).

Interestingly, in FEPSO, BBB disturbance was not purely restricted to the hippocampus but was also revealed in presubiculum, subiculum, amygdala, piriform lobe and, more rarely, in areas such as basal ganglia and hypothalamus. The larger limbic areas were also found to be affected in MR T2-weighted FLAIR scans showing signal as well as volume increase. In human LGI1 encephalitis, hippocampal and amygdaloidal swelling, followed 
by atrophy of the affected areas, have been observed in MRI studies $(35,36,38)$. Subsequently, considering the similarities in histopathology between human and feline hippocampi, and considering similar MRI changes in the human and feline hippocampus as well as amygdala, it can be assumed that in human LGI1 encephalitis, the amygdala might be similarly affected by BBB leakage and neurodegeneration as shown here in cats. Among patients with anti-LGI1 encephalitis, hypothalamic dysfunction in form of hyponatremia due to the syndrome of inappropriate antidiuretic hormone secretion $[\sim 60 \%$ of patients $(5,6)]$ and basal ganglia involvement in form of faciobrachial dystonic seizures [ $50 \%$ of patients (8)] are readily known. Cerebellar affects have only rarely been reported in human LGI1 encephalitis cases $(5,23,24)$. In our cats, hyponatremia and neurodegeneration of the hypothalamus as well as basal ganglia was seen occasionally. On the other hand, no cerebellar symptoms were observed, and we found neither BBB leakage and complement activation nor neurodegeneration in the cerebellum.

An important finding in this study of FEPSO is that BBB leakage was more restricted to specific areas associated with the limbic system, whereas $\mathrm{T}$ cell infiltrates were present brain wide. A clear finding in animal models of multiple sclerosis and neuromyelitis optica is that activated $\mathrm{T}$ cells can open the BBB and thereby enable antibodies to enter the CNS (39-44). Here, in FEPSO, however, $\mathrm{T}$ cell infiltrates and BBB leakage do not seem to overlap, since brain areas with high LGI1 abundance, such as the cerebellum (22), are spared of complement activation and neurodegeneration, despite a comparable number of infiltrating T cells. Therefore, this finding point toward another mechanism or an additional trigger that is required to induce local disturbance of the $\mathrm{BBB}$. It has been shown repeatedly that cytokines, peripheral, or in the CNS, have a drastic effect on $\mathrm{BBB}$ permeability (45-49). Intrastriatal injection of interleukin-1 $\beta$ has been shown to profoundly alter BBB permeability, leading to complement activation in Lewis rats (46). Interferon- $\gamma$ and tumor necrosis factor- $\alpha$ have been shown to decrease tight junction proteins, such as occludin $(47,50)$. Moreover, oxidative stress and cytokines have been reported to change phosphorylation patterns of various tight junction proteins, among them occludin, e-cadherin, and ZO-1, thereby dissociating the tight junction complexes $(51,52)$. However, to explain the selective breach of the BBB in FEPSO, other factors can also come into play. These are, for example, differences in permeability of the $\mathrm{BBB}$, which have been reported in mice $(53,54)$. Moreover, differential expression of receptors on the microvasculature in the brain can lead to different alterations in BBB permeability (55). Furthermore, external factors can also be involved in the opening of the BBB. High adrenaline levels caused by trauma or extreme exercise, cocaine, and nicotine have an effect on BBB permeability (55). Animal studies with NR2-antibodies showed that additional factors, such as lipopolysaccharides and epinephrine, can open the $\mathrm{BBB}$ in distinct locations and, therefore, the same antibodies can cause different symptoms $(56,57)$. Finally, here, we showed increased immunoglobulin leakage in the hippocampus of cats with LGI1 antibodies when compared with normal control cats. However, compared with epileptic controls, no difference was found. This is not surprising as it has been shown repeatedly that $\mathrm{BBB}$ dysfunction can result in epilepsy and seizures, which in turn can lead to disturbances in the BBB, resulting in a vicious circle (58-62).

To summarize, in this naturally occurring animal model, we were able to show that BBB disturbance and neurodegeneration in FEPSO is restricted to the hippocampus and other limbic structures, but is not found in other areas such as the cerebellum despite the presence of T cell infiltrates. Our findings broaden the perspective on LGI1 encephalitis by not only looking at the target organ (the brain parenchyma) but also on the question of how the presumably pathogenic antibodies can enter it. This not only deepens the knowledge and understanding of LGI1 encephalitis but also leads to new questions regarding regional selectivity of dysfunctional BBB. These findings are not only of use in veterinary medicine but also are highly relevant to human disease. A better understanding of underlying disease mechanisms will help to ameliorate future treatments and hopefully minimize remaining cognitive deficits of patients.

\section{ETHICS STATEMENT}

The project was discussed and approved by the institutional ethics committee (University of Veterinary Medicine, Vienna) in accordance with GSP guidelines and national legislation. In addition, all animal owners have given their consent.

\section{AUTHOR CONTRIBUTIONS}

JB and AP designed and supervised the project. AT and JB prepared the manuscript. AT performed the statistical analysis and, together with JB, the data interpretation. AT, MF, and LQ-G performed immunohistochemical staining, cell quantification, and imaging. AK performed the necropsies. SK provided MRI scans and interpretation of those. CB contributed to the study design. All authors reviewed the manuscript.

\section{ACKNOWLEDGMENTS}

The authors thank Ulrike Köck, Marianne Leisser, and Angela Kury for skilled technical assistance.

\section{FUNDING}

This project was financially supported by the Austrian Science Fund (project number P 26179-B24).

\section{SUPPLEMENTARY MATERIAL}

The Supplementary Material for this article can be found online at http://www.frontiersin.org/article/10.3389/fimmu.2017.01364/ full\#supplementary-material. 


\section{REFERENCES}

1. Dalmau J, Gleichman AJ, Hughes EG, Rossi JE, Peng X, Lai M, et al. AntiNMDA-receptor encephalitis: case series and analysis of the effects of antibodies. Lancet Neurol (2008) 7:1091-8. doi:10.1016/S1474-4422(08) 70224-2

2. Lai M, Hughes EG, Peng X, Zhou L, Gleichman AJ, Shu H, et al. AMPA receptor antibodies in limbic encephalitis alter synaptic receptor location. Ann Neurol (2009) 65:424-34. doi:10.1002/ana.21589

3. Lancaster E, Lai M, Peng X, Hughes E, Constantinescu R, Raizer J, et al. Antibodies to the GABAB receptor in limbic encephalitis with seizures: case series and characterisation of the antigen. Lancet Neurol (2010) 9:67-76. doi:10.1016/S1474-4422(09)70324-2

4. Vincent A, Buckley C, Schott JM, Baker I, Dewar B-KK, Detert N, et al. Potassium channel antibody-associated encephalopathy: a potentially immunotherapy-responsive form of limbic encephalitis. Brain (2004) 127:701-12. doi:10.1093/brain/awh077

5. Irani SR, Alexander S, Waters P, Kleopa KA, Pettingill P, Zuliani L, et al. Antibodies to Kv1 potassium channel-complex proteins leucine-rich, glioma inactivated 1 protein and contactin-associated protein- 2 in limbic encephalitis, Morvan's syndrome and acquired neuromyotonia. Brain (2010) 133:2734-48. doi:10.1093/brain/awq213

6. Lai M, Huijbers MGM, Lancaster E, Graus F, Bataller L, Balice-Gordon R, et al. Investigation of LGI1 as the antigen in limbic encephalitis previously attributed to potassium channels: a case series. Lancet Neurol (2010) 9:776-85. doi:10.1016/S1474-4422(10)70137-X

7. Ariño H, Armangué T, Petit-Pedrol M, Sabater L, Martinez-Hernandez E, Hara M, et al. Anti-LGI1-associated cognitive impairment. Neurology (2016) 87:759-65. doi:10.1212/WNL.0000000000003009

8. van Sonderen A, Thijs RD, Coenders EC, Jiskoot LC, Sanchez E, de Bruijn MAAM, et al. Anti-LGI1 encephalitis. Neurology (2016) 87:1449-56. doi:10.1212/WNL.0000000000003173

9. Finke C, Prüss H, Heine J, Reuter S, Kopp UA, Wegner F, et al. Evaluation of cognitive deficits and structural hippocampal damage in encephalitis with leucine-rich, glioma-inactivated 1 antibodies. JAMA Neurol (2017) 74:50-9. doi:10.1001/jamaneurol.2016.4226

10. Navarro V, Kas A, Apartis E, Chami L, Rogemond V, Levy P, et al. Motor cortex and hippocampus are the two main cortical targets in LGI1-antibody encephalitis. Brain (2016) 139:1079-93. doi:10.1093/brain/aww012

11. Frisch C, Malter MP, Elger CE, Helmstaedter C. Neuropsychological course of voltage-gated potassium channel and glutamic acid decarboxylase antibody related limbic encephalitis. Eur J Neurol (2013) 20:1297-304. doi:10.1111/ ene. 12186

12. Kitten S, Gupta N, Bloch RM, Dunham CK. Voltage-gated potassium channel antibody associated mood disorder without paraneoplastic disease. Biol Psychiatry (2011) 70:e15-7. doi:10.1016/j.biopsych.2011.03.016

13. LeDoux J, Cardinal RN, Everitt BJ, Charney D, Davidson R, Erwin W, et al. The amygdala. Curr Biol (2007) 17:R868-74. doi:10.1016/j.cub.2007.08.005

14. Melzer N, Budde T, Stork O, Meuth SG. Limbic encephalitis: potential impact of adaptive autoimmune inflammation on neuronal circuits of the amygdala. Front Neurol (2015) 6:171. doi:10.3389/fneur.2015.00171

15. Bien CG, Vincent A, Barnett MH, Becker AJ, Blümcke I, Graus F, et al. Immunopathology of autoantibody-associated encephalitides: clues for pathogenesis. Brain (2012) 135:1622-38. doi:10.1093/brain/aws082

16. Klang A, Schmidt P, Kneissl S, Bagó Z, Vincent A, Lang B, et al. IgG and complement deposition and neuronal loss in cats and humans with epilepsy and voltage-gated potassium channel complex antibodies. J Neuropathol Exp Neurol (2014) 73:403-13. doi:10.1097/NEN.0000000000000063

17. Ohkawa T, Fukata Y, Yamasaki M, Miyazaki T, Yokoi N, Takashima H, et al. Autoantibodies to epilepsy-related LGI1 in limbic encephalitis neutralize LGI1-ADAM22 interaction and reduce synaptic AMPA receptors. J Neurosci (2013) 33:18161-74. doi:10.1523/JNEUROSCI.3506-13.2013

18. Pakozdy A, Gruber A, Kneissl S, Leschnik M, Halasz P, Thalhammer JG. Complex partial cluster seizures in cats with orofacial involvement. J Feline Med Surg (2011) 13:687-93. doi:10.1016/j.jfms.2011.05.014

19. Claßen AC, Kneissl S, Lang J, Tichy A, Pakozdy A. Magnetic resonance features of the feline hippocampus in epileptic and non-epileptic cats: a blinded, retrospective, multi-observer study. BMC Vet Res (2016) 12:165. doi:10.1186/ s12917-016-0788-3
20. Pakozdy A, Halasz P, Klang A, Bauer J, Leschnik M, Tichy A, et al. Suspected limbic encephalitis and seizure in cats associated with voltage-gated potassium channel (VGKC) complex antibody. J Vet Intern Med (2013) 27:212-4. doi:10.1111/jvim.12026

21. Furlan S, Roncaroli F, Forner F, Vitiello L, Calabria E, PiquerSirerol S, et al. The LGI1/epitempin gene encodes two protein isoforms differentially expressed in human brain. J Neurochem (2006) 98:985-91. doi:10.1111/j.1471-4159.2006.03939.x

22. Herranz-Pérez V, Olucha-Bordonau FE, Morante-Redolat JM, PérezTur J. Regional distribution of the leucine-rich glioma inactivated (LGI) gene family transcripts in the adult mouse brain. Brain Res (2010) 1307:177-94. doi:10.1016/j.brainres.2009.10.013

23. Irani SR, Michell AW, Lang B, Pettingill P, Waters P, Johnson MR, et al. Faciobrachial dystonic seizures precede Lgil antibody limbic encephalitis. Ann Neurol (2011) 69:892-900. doi:10.1002/ana.22307

24. Steriade C, Day GS, Lee L, Murray BJ, Fritzler MJ, Keith J. LGI1 autoantibodies associated with cerebellar degeneration. Neuropathol Appl Neurobiol (2014) 40:645-9. doi:10.1111/nan.12132

25. Boesebeck F, Schwarz O, Dohmen B, Graef U, Vestring T, Kramme C, et al. Faciobrachial dystonic seizures arise from cortico-subcortical abnormal brain areas. J Neurol (2013) 260:1684-6. doi:10.1007/s00415-013-6946-7

26. Flanagan EP, Kotsenas AL, Britton JW, McKeon A, Watson RE, Klein CJ, et al. Basal ganglia T1 hyperintensity in LGI1-autoantibody faciobrachial dystonic seizures. Neurol Neuroimmunol Neuroinflamm (2015) 2:e161. doi:10.1212/ NXI.0000000000000161

27. López Chiriboga AS, Siegel JL, Tatum WO, Shih JJ, Flanagan EP. Striking basal ganglia imaging abnormalities in LGI1 ab faciobrachial dystonic seizures. Neurol Neuroimmunol Neuroinflamm (2017) 4:e336. doi:10.1212/ NXI.0000000000000336

28. Szots M, Blaabjerg M, Orsi G, Iversen P, Kondziella D, Madsen CG, et al. Global brain atrophy and metabolic dysfunction in LGI1 encephalitis: a prospective multimodal MRI study. J Neurol Sci (2017) 376:159-65. doi:10.1016/j. jns.2017.03.020

29. Urbach H, Rauer S, Mader I, Paus S, Wagner J, Malter MP, et al. Supratentorial white matter blurring associated with voltage-gated potassium channel-complex limbic encephalitis. Neuroradiology (2015) 57:1203-9. doi:10.1007/ s00234-015-1581-x

30. Hametner S, Wimmer I, Haider L, Pfeifenbring S, Brück W, Lassmann H. Iron and neurodegeneration in the multiple sclerosis brain. Ann Neurol (2013) 74:848-61. doi:10.1002/ana.23974

31. Mikula S, Trotts I, Stone JM, Jones EG. Internet-enabled high-resolution brain mapping and virtual microscopy. Neuroimage (2007) 35:9-15. doi:10.1016/j. neuroimage.2006.11.053

32. Blümcke I, Thom M, Aronica E, Armstrong DD, Bartolomei F, Bernasconi A, et al. International consensus classification of hippocampal sclerosis in temporal lobe epilepsy: a task force report from the ILAE commission on diagnostic methods. Epilepsia (2013) 54:1315-29. doi:10.1111/epi.12220

33. Miller TD, Chong TT-J, Aimola Davies AM, Ng TWC, Johnson MR, Irani SR, et al. Focal CA3 hippocampal subfield atrophy following LGI1 VGKC-complex antibody limbic encephalitis. Brain (2017) 140:1212-9. doi:10.1093/brain/awx070

34. Irani SR, Bien CG, Lang B. Autoimmune epilepsies. Curr Opin Neurol (2011) 24:146-53. doi:10.1097/WCO.0b013e3283446f05

35. Urbach H, Soeder BM, Jeub M, Klockgether T, Meyer B, Bien CG. Serial MRI of limbic encephalitis. Neuroradiology (2006) 48:380-6. doi:10.1007/ s00234-006-0069-0

36. Wagner J, Schoene-Bake JC, Malter MP, Urbach H, Huppertz HJ, Elger CE, et al. Quantitative FLAIR analysis indicates predominant affection of the amygdala in antibody-associated limbic encephalitis. Epilepsia (2013) 54:1679-87. doi:10.1111/epi.12320

37. Barkovich AJ. Concepts of myelin and myelinization in neuroradiology. Am J Neuroradiol (2000) 21:1099-109. doi:10.1016/S0006-3223(01)01323-3

38. Wagner J, Witt J-A, Helmstaedter C, Malter MP, Weber B, Elger CE. Automated volumetry of the mesiotemporal structures in antibody-associated limbic encephalitis. J Neurol Neurosurg Psychiatry (2015) 86:735-42. doi:10.1136/ jnnp-2014-307875

39. Babbe H, Roers A, Waisman A, Lassmann H, Goebels N, Hohlfeld R, et al. Clonal expansions of $\mathrm{CD} 8(+) \mathrm{T}$ cells dominate the $\mathrm{T}$ cell infiltrate in active multiple sclerosis lesions as shown by micromanipulation and single cell 
polymerase chain reaction. JExp Med (2000) 192:393-404. doi:10.1084/ jem.192.3.393

40. Bradl M, Misu T, Takahashi T, Watanabe M, Mader S, Reindl M, et al. Neuromyelitis optica: pathogenicity of patient immunoglobulin in vivo. Ann Neurol (2009) 66:630-43. doi:10.1002/ana.21837

41. Jones MV, Huang H, Calabresi PA, Levy M. Pathogenic aquaporin-4 reactive $\mathrm{T}$ cells are sufficient to induce mouse model of neuromyelitis optica. Acta Neuropathol Commun (2015) 3:28. doi:10.1186/s40478-015-0207-1

42. Lassmann H, Brück W, Lucchinetti CF. The immunopathology of multiple sclerosis: an overview. Brain Pathol (2007) 17:210-8. doi:10.1111/j.1750-3639.2007.00064.x

43. Linington C, Bradl M, Lassmann H, Brunner C, Vass K. Augmentation of demyelination in rat acute allergic encephalomyelitis by circulating mouse monoclonal antibodies directed against a myelin/oligodendrocyte glycoprotein. Am J Pathol (1988) 130:443-54.

44. Zeka B, Hastermann M, Hochmeister S, Kögl N, Kaufmann N, Schanda K, et al. Highly encephalitogenic aquaporin 4-specific T cells and NMO-IgG jointly orchestrate lesion location and tissue damage in the CNS. Acta Neuropathol (2015) 130:783-98. doi:10.1007/s00401-015-1501-5

45. de Vries HE, Kooij G, Frenkel D, Georgopoulos S, Monsonego A, Janigro D. Inflammatory events at blood-brain barrier in neuroinflammatory and neurodegenerative disorders: implications for clinical disease. Epilepsia (2012) 53(Suppl 6):45-52. doi:10.1111/j.1528-1167.2012.03702.x

46. Kitic M, Hochmeister S, Wimmer I, Bauer J, Misu T, Mader S, et al. Intrastriatal injection of interleukin-1 beta triggers the formation of neuromyelitis optica-like lesions in NMO-IgG seropositive rats. Acta Neuropathol Commun (2013) 1:5. doi:10.1186/2051-5960-1-5

47. Minagar A, Alexander JS. Blood-brain barrier disruption in multiple sclerosis. Mult Scler (2003) 9:540-9. doi:10.1191/1352458503ms965oa

48. Pan W, Stone KP, Hsuchou H, Manda VK, Zhang Y, Kastin AJ. Cytokine signaling modulates blood-brain barrier function. Curr Pharm Des (2011) 17:3729. doi:10.2174/138161211798220918

49. Varatharaj A, Galea I. The blood-brain barrier in systemic inflammation. Brain Behav Immun (2017) 60:1-12. doi:10.1016/j.bbi.2016.03.010

50. Oshima T, Laroux FS, Coe LL, Morise Z, Kawachi S, Bauer P, et al. Interferon- $\gamma$ and interleukin-10 reciprocally regulate endothelial junction integrity and barrier function. Microvasc Res (2001) 61:130-43. doi:10.1006/mvre.2000.2288

51. Nwariaku FE, Chang J, Zhu X, Liu Z, Duffy SL, Halaihel NH, et al. The role of p38 map kinase in tumor necrosis factor-induced redistribution of vascular endothelial cadherin and increased endothelial permeability. Shock (2002) 18:82-5. doi:10.1097/00024382-200207000-00015

52. Rao RK, Basuroy S, Rao VU, Karnaky KJ Jr, Gupta A. Tyrosine phosphorylation and dissociation of occludin-ZO-1 and E-cadherin-beta-catenin complexes from the cytoskeleton by oxidative stress. Biochem J (2002) 368:471-81. doi:10.1042/BJ20011804

53. Phares TW, Kean RB, Mikheeva T, Hooper DC. Regional differences in blood-brain barrier permeability changes and inflammation in the apathogenic clearance of virus from the central nervous system. J Immunol (2006) 176:7666-75. doi:10.4049/jimmunol.176.12.7666

54. Tonra JR, Reiseter BS, Kolbeck R, Nagashirma K, Robertson R, Keyt B, et al. Comparison of the timing of acute blood-brain barrier breakdown to rabbit immunoglobulin $\mathrm{G}$ in the cerebellum and spinal cord of mice with experimental autoimmune encephalomyelitis. J Comp Neurol (2001) 430:131-44. doi:10.1002/1096-9861(20010129)430:1<131:AID-CNE1019>3.0. $\mathrm{CO} ; 2-\mathrm{K}$

55. Diamond B, Huerta PT, Mina-osorio P, Kowal C, Volpe BT. Losing your nerves? Maybe it's the antibodies. Nat Rev Immunol (2009) 9:449-56. doi:10.1038/nri2529

56. Huerta PT, Kowal C, DeGiorgio LA, Volpe BT, Diamond B. Immunity and behavior: antibodies alter emotion. Proc Natl Acad Sci U S A (2006) 103:678-83. doi:10.1073/pnas.0510055103

57. Kowal C, DeGiorgio LA, Nakaoka T, Hetherington H, Huerta PT, Diamond B, et al. Cognition and immunity: antibody impairs memory. Immunity (2004) 21:179-88. doi:10.1016/j.immuni.2004.07.011

58. Friedman A. Blood-brain barrier dysfunction, status epilepticus, seizures, and epilepsy: a puzzle of a chicken and egg? Epilepsia (2011) 52:19-20. doi:10.1111/j.1528-1167.2011.03227.x

59. Marchi N, Granata T, Ghosh C, Janigro D. Blood-brain barrier dysfunction and epilepsy: pathophysiologic role and therapeutic approaches. Epilepsia (2012) 53:1877-86. doi:10.1111/j.1528-1167.2012.03637.x

60. Michalak Z, Lebrun A, Di Miceli M, Rousset M-C, Crespel A, Coubes P, et al. IgG leakage may contribute to neuronal dysfunction in drug-refractory epilepsies with blood-brain barrier disruption. J Neuropathol Exp Neurol (2012) 71:826-38. doi:10.1097/NEN.0b013e31826809a6

61. Van Vliet EA, Araújo SDC, Redeker S, Van Schaik R, Aronica E, Gorter JA. Blood-brain barrier leakage may lead to progression of temporal lobe epilepsy. Brain (2007) 130:521-34. doi:10.1093/brain/awl318

62. Vezzani A, Granata T. Brain inflammation in epilepsy: experimental and clinical evidence, brain inflammation in epilepsy: experimental and clinical evidence. Epilepsia (2005) 46:1724-43. doi:10.1111/j.1528-1167.2005. 00298.x

Conflict of Interest Statement: CB gave scientific advice to Eisai (Frankfurt, Germany) and UCB (Monheim, Germany), undertook industry-funded travel with support of Eisai (Frankfurt, Germany), UCB (Monheim, Germany), Desitin (Hamburg, Germany), and Grifols (Frankfurt, Germany), obtained honoraria for speaking engagements from Eisai (Frankfurt, Germany), UCB (Monheim, Germany), Desitin (Hamburg, Germany), Diamed (Köln, Germany), Fresenius Medical Care (Bad Homburg, Germany), Biogen (Ismaning, Germany), and Euroimmun (Lübeck, Germany). He received research support from Diamed (Köln, Germany) and Fresenius Medical Care (Bad Homburg, Germany). He is a consultant to the Laboratory Krone, Bad Salzuflen, Germany, regarding neural antibodies and therapeutic drug monitoring for antiepileptic drugs. The other authors declare no competing financial interests.

Copyright $\odot 2017$ Tröscher, Klang, French, Quemada-Garrido, Kneissl, Bien, Pákozdy and Bauer. This is an open-access article distributed under the terms of the Creative Commons Attribution License (CC BY). The use, distribution or reproduction in other forums is permitted, provided the original author(s) or licensor are credited and that the original publication in this journal is cited, in accordance with accepted academic practice. No use, distribution or reproduction is permitted which does not comply with these terms. 